\title{
Limitations of knowledge management
}

\author{
V. Newman \\ Department of Computer Integrated Manufacturing Cranfield University, UK \\ v.newman@cranfield.ac.uk \\ www.cranfield.ac.uk/sims/staff/staff_cim_newman.htm
}

\section{Contents}

The problem begins with language

Innovate or die

Creating and delivering new forms of knowledge: the knowedge opportunity

Understanding the ecology and interactions of the innovating stereotypes

Conclusions

References

\section{The problem begins with language}

The problems of knowledge management begin with the issue of language: knowledge is a dangerously inclusive word. The moment a consultant, academic or a politician says that the meaning of a particular word does not matter, that is the moment to take very special care of everything that follows. The other problem lies in having too much unspecified 'knowledge' and not enough knowledge about knowledge itself.

This special care is necessary since the trend for existing professionals in learning organisations, lean production management and IT professionals is to rebadge their old products as new knowledge management technologies. It is sad to see the commoditisation of an idea that had value before it was even understood. Similarly, knowledge management has suffered from traditional 'faditisation' and has already followed the traditional cycle of enthusiasm, books and conferences, through to despair and ultimately the final indignity of inclusion within an UK Government white-paper.

Back to words and their meanings. There are two immediate problems with knowledge. First, it is enormously inclusive, embracing a broad range of terms like data, data structures, myths, intelligence, rumours, and even information. The second relates to the act of 'knowing' which implies that knowledge is defined by awareness: in other words, what you are aware of, is what you know.

These levels of difficulty were compounded by the accidental combination of Platt of HP's famous saying: 'If HP knew what HP knows'; Nonaka and Takeuchi's (1995) linguistic confusion that led to a false dichotomy of tacit and explicit knowledge, and the awareness that downsizing in corporations had destroyed functional expertise. All that remained was for consultants to misuse Francis Bacon's 'Knowledge is power' quote and the knowledge revolution took a major wrong-turning and started to capture 
personal expertise and best practices in the form of documented processes and made this expertise available via intranets. And of course, much of this 'knowledge' (what some people know) was about processes that delivered commodities whose market price was declining. The appeal of this 'knowledge' management revolution for many lay in its apparent similarity with lean manufacturing. This linkage meant salesmen didn't need to learn anything new, old IT products and lean mass manufacturing concepts could be wrapped in the old misunderstood learning organisation packaging and rebranded with new associations.

The clues to the future of knowledge work lie in the experiences of Shell and BP. Both invested in managing a mistaken form of 'knowledge' and both have experienced major layoffs and financial crises. In this way, the definition of 'knowledge' begins to become clearer: it is probably nothing to do with processes for delivering commodities, or even stable processes but more to do with the future than the recent past.

Looking at the word, 'management', the problem is compounded by its associations. The implication is that knowledge is a product that could be managed; that it is a matter of managing a discrete resource where the paradigm is one of storage, conservation and logical deployment. In all the CEO knowledge visualisation workshops participants have questioned the usefulness of the term 'knowledge management' (Newman 1998).

It was interesting chairing a conference last year to find organisations that chose not to use the term and who appear to be successful or, at any rate, profitable as a result. It seems as though the associations of the term 'knowledge management' actually create more confusion than success. The emphasis on knowledge management is bedevilled by false associations with computers. Building on De Bono's suggestion that the purpose of thinking is to remove the need to think, perhaps the problem with the prevailing 'industrial' paradigm surrounding knowledge management lies in its removing the need to think about doing anything new.

\section{Innovate or die}

BMW's attempt to leverage a UK government subsidy for the Rover Longbridge auto assembly plant was based on the argument that its survival required significant plant productivity gains, while at the same time Peugot was recruiting a new workforce to build an attractive new car, the Peugot 206, a few miles down the road. The futility of the optimisation mindset within the context of a global knowledge economy is clearly not understood by either government or some major organisations. It was only in 1996 that Steven Roach, the high-priest of downsizing and hollowing-out corporations chose to recant his highly profitable philosophy by saying that such lean strategies were ultimately recipes for industrial extinction (Roach 1996). Simultaneously, research at Cranfield directly connected the adoption of a primary strategy of optimising existing processes or products with an increasing degradation of an organisation's ability to innovate (Madgwick 1996).

Roach's recantation explicitly suggested that downsizing and efficiency was a betrayal of workforces by management, a management that was unable to innovate and so chose to optimise instead. The long-term danger of focusing on optimising products and processes is one of choosing to shift the basis of competition from differentiated value to price, of becoming the seller of capacity, having lost the ability to create new forms of knowledge and delivering them to a global economy in the form of new 
market values, and ultimately determining prices in the world market. The Japanese lean approach of optimisation and their approach to $\mathrm{R} \& \mathrm{D}$ are largely unable to deliver genuinely new products. The extension of lean production into the supply chain to enforce process control and reduced variation means that lean production acts as a brake on the potential rate of innovation through forcing its prisoners to compete on price and not on value (Herbig and Palumbo 1996; Kondo 1990).

It is only when CEOs and MDs within the supply-chain structure plot the pricereduction curve over time that they realise the nature of their dilemma, and begin to understand the need to move from continuous improvement to a higher rate of discontinuous improvement to outpace their necessary cost-reduction curve, creating a new unanticipated margin to invest in developing new customers in a more balanced risk-portfolio. In other words, lean production is just a strategy, and once it became public-domain it was no longer a competitive form of knowledge. This doesn't mean it can be ignored, it becomes part of the baseline but, like IT, is no longer a differentiator.

Returning to the automotive arena, the ultimate configuration of world car manufacture is probably going to lead to a regional, truly agile automotive plant jointly owned in a Keiretsu/Kaibatsu-type arrangement where different cars are made according to demand, and the factory itself is no longer seen as an asset but the ability to design new configurations of product becomes the core competence. In other words, the Nike approach of focusing on developing the ability to create and sell new products, concentrating on differentiating on product and brand associations and realising that manufacture and procurement is a commodity, is gradually migrating from streetfashion to the still-monolithic automotive sector.

A similar pattern of thought is emerging out of pharmaceutical/life science organisations. Global pharmaceuticals are probably closest to practically understanding the implications of Drucker's (1995) global knowledge economy in driving them to reconfigure their business models to align around an internal knowledge economy model. In other words, to compete within a Global knowledge economy whose real currency is ideas and the timing of their exploitation, it is necessary to focus on accelerating time-to-market processes in order to reduce investment over time and introduce the product at an acceptable price. The new thinking suggests that anything outside the creation and delivery of new market values is non-core and should be outsourced. This includes factories and project management, often mistaken as the heart of the business.

It seems as though the purpose of thinking is to create formulae that remove the need to think at all. Academics and organisations are always searching for formulae and tend to be surprised at the time-based nature of the models they create. This is the problem at the heart of knowledge management. In other words, whatever new forms of competitive knowledge are created, they degrade over time into becoming mere information, appearing in specialist journals, and then as mere data published and taught by academics.

\section{Back to top \\ 3. Creating and delivering new forms of knowledge: the knowledge opportunity}

The issue for organisations is how to balance their emphasis between knowledge management and knowledge development. By defining knowledge work as the 
continuum between these two extremes, organisations need to understand the continuum and take care with their location along it, to manage investment in both forms. Shell and BP led the world in their application of what we used to call IT to develop knowledge management, becoming very adept at the capture and re-use of expertise in structural/process capital involved in the delivery of what was rapidly becoming a commodity.

What was missing was the wake-up call from relevant scenario planning or learning exercises. In both organisations, scenario planning had become sidelined from the decision makers and misunderstood. The cue for shifting from knowledge management to developing new forms of knowledge is often based on the realisation that the existing assets are becoming seen as commodities. In this situation, you either create a knowledge wrap in the form of new, or tacit knowledge around the utilisation of the commodity that becomes more valuable than the original product or service, or you create a genuinely new form of knowledge. Shell and BP failed to develop new market values and ended up selling a commodity, they even failed to utilise the data from their customer loyalty cards to develop customer information patterns like Tesco (UK) and Merck (US) and exploit new positions either up or down the value chain. While global consultancies are often characterised as knowledge-based organisations in meeting the criteria for having high intellectual capital premiums (Stewart 1997) and low net fixed asset to gross market value rations, recent informal workshops with two out of the top five consultancies in the UK found no evidence of individuals creating new forms of knowledge that changed the way work was approached. Instead, knowledge was bought into the organisation, stabilised as a technology and optimised. This may mean that top consultancies are exploiting global positioning and brand associations, while turning out to be largely parasitic in terms of knowledge development.

Let us explore two everyday examples of knowledge. The next time you get into a black, taxi-cab in London, ask the driver about 'The Knowledge'. What can be learnt is fascinating. 'The Knowledge' is the ability to recall the 480 routes across London that make it unnecessary to carry a London A-Z to direct the driver. Does 'The Knowledge' represent the kind of knowledge we are interested in? Can we learn something about the kind of knowledge necessary to deliver knowledge leadership with the potential to make our business profitable? 'The Knowledge' is a useful differentiator, but once it became a standard it did not guarantee that the driver would make a profit.

In 1997 the North West Ambulance Trust featured on a Radio 4 Business programme as being unusual in the way it managed itself. You might think that the Trust had applied knowledge of its route-structures within the North West of England to optimise its response timings. This would only be a partial answer and would not really differentiate this service.

If we return to the black cab, the key to the driver's profitability lies not in 'The Knowledge' of the 480 memorised routes, but in the knowledge of where to be, at what time, to harvest the most profitable customer journeys. This knowledge or information remains fairly tacit. What the North West Ambulance Trust did was to create a new form of knowledge that was pattern-based by analysing their data of call-outs over previous years to look for patterns in timings, locations, and types of injuries to create a predictive schedule for pre-locating ambulances and paramedics before incidents occurred and, in so doing, deliver a service with new value.

So what is the knowledge opportunity? The answer lies in discerning time-based patterns whose exploitation creates new market values. The knowledge opportunity lies in deliberately creating new forms of knowledge out of understanding the patterns 
within our own data, in other words recognising the patterns over a period of time to create information. The most fundamental pattern to the global knowledge economy lies in understanding the commoditisation process that takes niche products and rapidly turns them into commodities.

Clearly, the competitive nature of knowledge in terms of value and time shows us that knowledge is not a static commodity, and its value lies in its exploitation to deliver new market values or expectations by destabilising existing positions of competitive products in terms of entry to market and relative value. Similarly, as Peter Drucker observed, it is too easy to confuse data with knowledge and information technology with information. If De Geus (1998) was right, and the only true competitive advantage lies in the ability to learn faster than the competition, then the nature and relationship of certain key words including data, information, knowledge and technology (DIKT) need to be understood and disciplines built around the emergent process that connects them and the context in which they may be applied.

The figure below connects these words within a transitional process. Let's begin by looking at the first transition between data and information, perhaps the most fundamental transition and certainly the most difficult to manage within the DIKT learning process below.

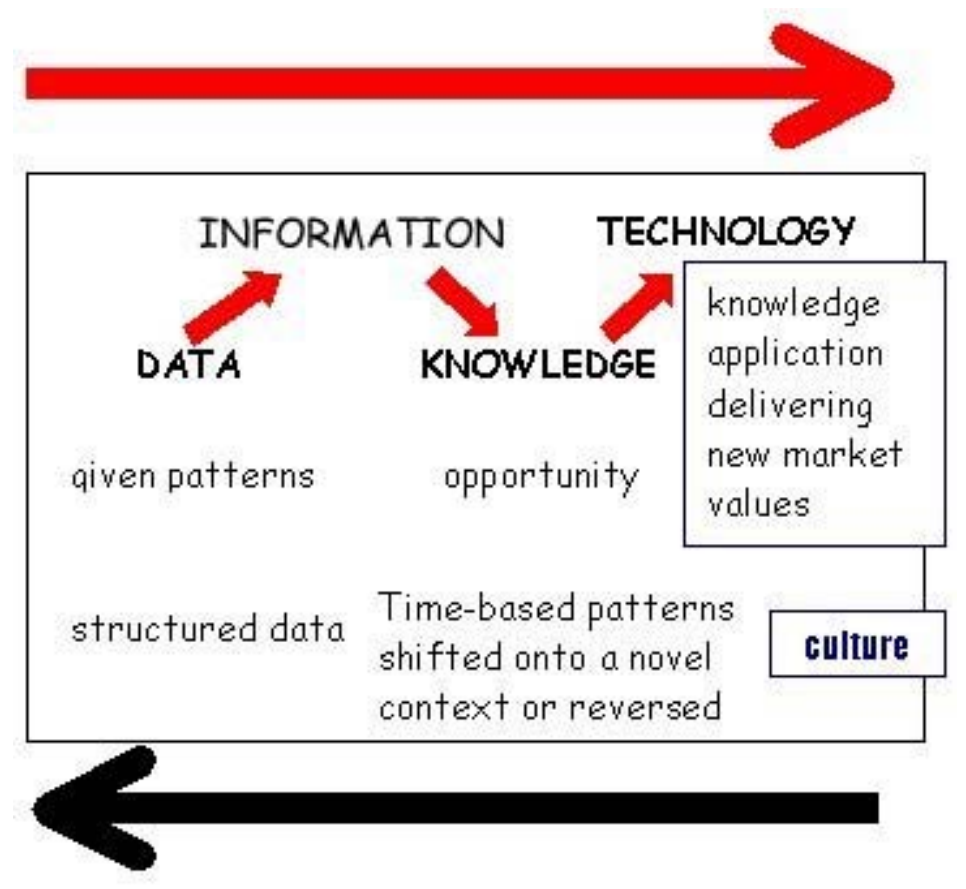

Back to top

1. From data to information

Basically, data exist in infinite volume and variety, but the transition from data into information remains problematical, as anyone knows who has attempted to teach statistical process control to either senior executives or shopfloor operatives. This transition is difficult because we confuse data and information. Within the media and everyday business, they tend to be treated as the same thing. This means that we have professors of information technology who are really professors of data technology.

We confuse the meaning of the word 'information' with being informed. Similar confusion exists in articles about 'information overload' stresses being caused through the Internet. The overload stress that is being discussed is due to the difficulty individuals have in processing the variable-quality data available on 
the Internet and turning the data into usable information. In other words, we don'1 have time to make sense of it all and therein lies the clue as to the meaning of information. Information only exists when we can either see or create patterns or structures within the field of data. This information is highly contextual and defir by the means of collection, the media of presentation and the purpose involved.

2. From information to knowledge

\section{Back to top}

The next transition from information to knowledge is defined by an approach tha begins with the context of what is known about the past and with a style of thinki about the future as a process that identifies opportunities for delivering new mark values. This transition involves a creative technique that takes an existing pattern structure in an existing form of thinking and locates that pattern within a new, contrasting context or deliberately reverses its flow or direction. This essential patterning or P7 technique involves pattern recognition, making, breaking, playin reversing, shifting, and antithesis.

Useful examples include the development of the Stealth fighter technology from dense, Russian technical paper that predicted how to calculate geometric configurations to control electromagnetic reflections. A Lockheed mathematician read the paper to its end and realised that translating this thinking to the defensivt radar-systems context meant that the apparent size of an object could be reduced manipulating the shape of the attacking aircraft (Rich and Janos, 1994). Another example includes Richard Branson's approach to attacking markets by reversing 1 conventional logic that says avoid highly developed markets with virtual cartel management where the costs of entry are high. Branson realised that, over time, new niche customers are always emerging within such a stable market and if this group is targeted through new market values, the existing stable cartels can be destabilised and profitable fragments can be picked off. Andy Grove's (1996) control of the ' 86 chip market is the most blatant example of time-based pattern exploitation where a single organisation managed the behaviour of an entire industry and deliberately slowed the pace of industrial innovation to fully exploit investment in a single technology.

Two interesting examples of future knowledge as opportunities that are currently under development include the use of product data management systems out of their original engineering context and the application of supply-chain methodologies out of their original automotive context and with a reversal of original direction away from supplier to customer. Financial services organisatior are working on developing product data management systems to allow the decomposition of product features across a range of existing offerings to create $n$ product offerings specifically customised to offer novel combinations that meet evolving customer expectations. Similarly, the reversal of supply-chain management technology through 180 degrees creates a new approach which can 1 tentatively described as customer portfolio management. Customer portfolio management is the CEO strategy described earlier for reversing the tendency of supply-chain management strategies to commoditise supplier products, subassemblies or processes by adopting the perspective of the supplier to quantify th risk, devaluation of value, the farming of profit, and the requirement to develop risk-reduction strategies that lead to a more balanced portfolio of customers. 
3. From knowledge to technology

The final, difficult stage of the process is the exploitation of knowledge as an opportunity within the form of an application or a technology. This final phase involves the organisation in developing stable processes and a culture that is the product of learning to overcome a series of crises to stabilise the technology that delivers the products that create new expectations in the market. The DIKT learning process is time and value-based. Over a period of time, the leading technology introduces the new standard, this becomes an opportunity or form of knowledge for emulators, which over time becomes information as the patterns become obvious until it becomes public domain.

Creativity is essential to this process; creativity to adopt new perspectives in order to recognise or create new patterns, creativity to play and reverse these patterns within contrasting contexts, and finally creativity to manage the process of learning through anticipating and solving the problems of implementing the technology in a stable form. But this creativity requires creative people with different approaches to their creativity and knowledge management is largely developed by people who prefer to ignore the need to understand creativity, creative interactions and the need to focus on creating new forms of knowledge.

\section{Back to top}

\section{Understanding the ecology and interactions of the innovating stereotypes}

Unfortunately, creativity is very largely intrinsically motivated, whether involved in optimising to improve performance or innovating to create new expectations. If we understand the largely intrinsic nature of motivation behind creative behaviour and if we connect this understanding or information with the DIKT learning process, then it becomes essential to understand the nature of these 'innovating stereotypes' which combine to deliver new technologies.

Over a period of years, an intriguing and misleading statistic of $80 \%$ has been ascribed to the failure-rate of systematic change programmes (Newman 1997). It is noticeable that the content of serious books about implementing change in organisations is largely taken up with how to manage project programmes or concurrent projects. Why is this? The innovating stereotypes were developed to explain this problem of failure and repetitive presentation of information on how to implement.

The innovating stereotypes consist of three essential stereotypical behaviours that are essential for organisations to continue to innovate. The model does not suggest that there are three discrete populations, but that individuals have different predispositions toward all three crude behaviours. The innovating stereotypes can loosely be described as populations who must interact to deliver successful innovating performance. These populations are described as creators, implementors and stabilisors.

A useful illustration of the model and the interactions of the stereotypes lies behind the story of the arrival of graphical user interface technology (GUI) pioneered by Xerox's Palo Alto Research Center and delivered by Steve Jobs of Apple (Raganatu Nayak and Ketteringham 1995). Xerox set up its computer systems laboratory, as insurance against the paperless office, under Bob Taylor who filled his flat organisation with creators whose only task was to come up with new ideas and turn them into stable prototypes. Unfortunately, Taylor's introverted creators found it impossible to translate 
their technologies into the world of the Xerox stabililisor executives.

In December 1979, Steve Jobs attended a demonstration and recognised the opportunity that the prototypical GUI technology offered. He had a context for application and a hunger to deliver a stable, customer-friendly technology. Jobs demanded another demonstration and returned with the Apple programming team. Apparently within one hour, Jobs's team understood the implications of the technology and within another hour had spotted the mistakes and suggested improvement. Jobs was lucky to see the CSL PARC demonstration developed by the Xerox creators, whose technology was a stable prototype. Jobs came along and acted as implementor, developing GUI as an implementor technology via LISA (the 16-bit microprocessor, bit-mapped display, a mouse for controlling the on-screen cursor and a keyboard that was separate from the main computer box). LISA failed, but was itself an implementor prototype that led to the stabilised technology that enabled the Apple Macintosh that introduced the new standard in computing by delivering new market values.

Jobs's success lay in his ability to bridge the gap between creators and stabilisors. All three stereotypes are interdependent. Between the future thinking of the creator (what could be), sits the now-thinking of the implementor (how to make it happen, how) and the stabilisor's measurement of today's performance in terms of the past. The explanation for the high failure-rate of systemic change programmes lies in the stabilisor's role in commissioning the change programme. Being a stabilisor, the future can only be imagined in terms of the past. Stabilisors will always be disappointed with their purchase of change because they want something they cannot have which is change without change. Having driven their own source of change out of their business in order to optimise it, they attempt to purchase a step-change technology that contradicts their existing culture, and the pain of attempting and failing to change is traumatic. The innovating stereotypes model can also be retrospectively applied to the famous 3M Post-It story (Cingely 1996). Thus Spencer Silver is the creator who decided to play with an adhesive formula to see what might happen if the variables were shifted, created an adhesive which wasn't an adhesive, and spent five years trying to sell it internally within 3M. Arthur Fry, as a part-time choir-director, had a context for an adhesive that had no memory for marking places in scores. He was a classic implementor and managed to interest Geoffrey Nicholson and Joseph Ramsay in building a case and fighting the marketing paradigm that only saw opportunities in market gaps and did not understand market-making by the introduction of products with new market values. The rest of the story is the interaction of implementors and stabilisors basically problem-solving the technology.

The explanation of the high proportion of content of serious change literature being identical lies in the inability of stabilisors to absorb the lessons from change programmes since these imply continual instability. A contributor is the expulsion of implementors who burnt their political bridges in fighting to implement the unsatisfactory change programme and have to leave the stabilisor-dominated organisation, or have realised their implementor nature. These change books are popular with stabilisors because they remain data, and are not translated into information of knowledge in the form of opportunities. In other words, stabilisors cannot learn how to change which means that they have to outsource their implementors through consultancies, and are predisposed to optimisation strategies.

\section{Back to top}

\section{Conclusions}


1. There is a fundamental need to create new thinking about knowledge: a need to focus on knowledge about knowledge rather than rebadging old products and old thinking and calling it knowledge.

2. The knowledge-work continuum model is a means to balance interest in old products and processes with thinking about new opportunities. The knowledge issue requires understanding of the creative process and the importance of implementors in managing the relationship between creators and stabilisors.

3. Competition is the context for thinking about knowledge, it is within this context that time-based patterns that deliver new market values make sense. Disciplined use of language is essential for progress. Knowing what is possible without the potential to make it happen is meaningless, hence the need to balance new knowledge with an understanding of old knowledge around time to market.

4. Every business formula comes with a sell-by date. The key is to manage the timing of the crisis surrounding obsolescence and anticipate the next form of knowledge. If this is understood, then hopefully, this article is already obsolete.

Back to top

\title{
6. References
}

1. Cringely, R.X. 1996. Accidental empires. Harmondsworth: Penguin.

2. De Geus, A. 1988. Planning as learning. Harvard Business Review, March-April: 7074.

3. Drucker, P.F. 1993. Post-capitalist society. Oxford: Butterworth-Heinemann.

4. Grove, A.S. 1996. Only the paranoid survive. London: HarperCollins.

5. Herbig, P.A. and Palumbo, F.A. 1996. Innovation-Japanese style, Industrial Management \& Date Systems, Vol. 5.

6. Kondo, Y. 1990. Creativity in daily work. Human Systems Management, Vol. 9.

7. Madgwick, S. 1996. Overcoming barriers to manufacturing improvement, SIMS, Cranfield University, Unpublished $\mathrm{PhD}$ thesis.

8. Newman, V. 1997. Redefining knowledge management for competitive advantage. Journal of Knowledge Management, Vol. 1, No. 2.

9. Newman, V. 1998. CEOs visualising knowledge management. Journal of Knowledge Management, Vol. 1, No. 4.

10. Nonaka, I. and Takeuchi, H. 1995. The knowledge-creating company. Oxford University Press.

11. Ranganath Nayak, P. and Ketteringham, J.M. 1993. Breakthroughs. Didcot: Mercury.

12. Rich, B.R. and Janos, L. 1994. Skunk works. London: Warner.

13. Roach, S.S. 1996. A new competitive dilemma. The Global Borrowers and Investors' Forum, Euromoney Conference, London, 18 June.

14. Stewart, T. 1997. Intellectual capital. Doubleday.

\author{
V Newman \\ Department of Computer Integrated Manufacturing \\ Cranfield University, UK \\ v.newman@cranfield.ac.uk \\ http://www.cranfield.ac.uk/sims/staff/staff_cim_newman.htm
}

\section{Disclaimer}

Articles published in SAJIM are the opinions of the authors and do not necessarily reflect the opinion of the Editor, Board, Publisher, Webmaster or the Rand Afrikaans University. The user hereby waives any claim he/she/they may have or acquire against the 
publisher, its suppliers, licensees and sub licensees and indemnifies all said persons from any claims, lawsuits, proceedings, costs, special, incidental, consequential or indirect damages, including damages for loss of profits, loss of business or downtime arising out of or relating to the user's use of the Website. 